\title{
Pediatric tuberculosis in close contacts: prospective study
}

\author{
Saikumar $\mathbf{B}^{1}$, Tarakeswara Rao $\mathbf{P}^{2}$ \\ ${ }^{1}$ Dr. Bonela Saikumar, Assistant Professor ${ }^{2}$ Dr. Pikala Tarakeswara Rao, Professor, both authors are affiliated with the \\ Department of Pediatrics, Gitam Institute of Medical Sciences and Research, Visakhapatnam, Andhra Pradesh, India.
}

Corresponding Author: Dr. Pikala Tarakeswara Rao, Professor, Department of Pediatrics, Gitam Institute of Medical Sciences and Research, Visakhapatnam, Andhra Pradesh, India E-mail: ptrao1971@gmail.com

\begin{abstract}
Introduction: Tuberculosis continues to be a major cause of morbidity and mortality among children in developing country like India. Early detection and treatment of infection can reduce morbidity and mortality. Screening of children in close contact with high risk groups is universally recommended but seldom practiced in resource limited settings. Aims and objectives: Primary objective to find prevalence of tubercular infection in children who are household contacts of PTB, and HIV-PTB coinfected adults. To identify subset of contacts who are at higher risk of contacting infection. Settings and Design: Prospective study conducted in tertiary care center. Children aged $<10 y e a r s$ in contact with adult PTB and PTB with HIV were enrolled and evaluated for tuberculosis infection by clinical, radiographic, and tuberculin testing. Transverse in duration of greater than $10 \mathrm{~mm}$ was defined as positive tuberculin test suggestive of tubercular infection. Results: About $33.6 \%$ of contacts exposed were found to be infected. Tuberculin test was found to be significantly positive in contacts exposed to PTB and HIV-PTB co-infected adults groups ( $\mathrm{p}>0.0001$, with an odds ratio of $0.36(1.10-1.74)), \mathrm{P}>0.0001,2.77$ (1.33 - 5.79). Majority of children exposed to HIV negative PTB adults were infected compared to contacts exposed to HIV-PTB co-infected adults (35 vs 14) and the difference is statistically significant $(\mathrm{p}>0.001)$. Absence of scar is not associated with any significant risk. Conclusions: Prevalence of tuberculosis is high in contacts with high risk groups. HIV-PTB co-infected adults transmit infection less in comparison to HIV negative TB adults. Young children and those with severe malnutrition need to be targeted in contact screening.
\end{abstract}

Keywords: Contact tracing, Risk factors, Latent tuberculosis

\section{Introduction}

Pediatric tuberculosis infection and disease is widely prevalent in developing countries. It is estimated that around $10 \%$ of the 10.4 million global incident TB cases and 250,000 of the 1.7 million TB deaths in 2016 were amongst children ( $<15$ years) [1]. In high TB burden settings, it is estimated that childhood TB contributes to $15-20 \%$ of all TB cases and is one of the leading causes of childhood mortality [2]. Most children usually acquire infection from household contact.

Among the household contacts, $10 \%$ of children less than 5 years and $8 \%$ older children will develop TB [3]. Children have a higher risk of progression to active tuberculosis than adults and there is increased risk of extra pulmonary complications [4]. Early detection is important to break the chain of transmission and reduce morbidity and mortality [5]. Hence importance and urgent need for contact tracing is recognized but rarely

Manuscript received: $10^{\text {th }}$ June 2019

Reviewed: $20^{\text {th }}$ June 2019

Author Corrected: 24 ${ }^{\text {th }}$ June 2019

Accepted for Publication: $28^{\text {th }}$ June 2019 practiced in high burden countries. Contact screening and management of child contacts has great potential to reduce TB-related morbidity and mortality in children [6]. This study has been undertaken with the aim of studying the prevalence of tuberculosis infection among children in household contact with adults having HIV negative pulmonary tuberculosis and pulmonary tuberculosis with HIV and to identify possible risk factors. Identification of risk factors for disease among contacts may guide clinicians and public health practitioners on subsets of population that may benefit the most from contact tracing.

\section{Subjects and Methods:}

Setting and design: This prospective study was conducted in tertiary care institution of Andhra Pradesh from October 2017 to September 2018. Adults cases of pulmonary TB and adults with HIV and pulmonary TB co-infection were identified from registers of RNTCP and NACO units respectively. 
Sampling: Simple random sampling done and convenient sample technique adopted for the study. Total of 200 contacts were identified and called for screening. Total of 154 children came for screening and enrolled in study.

Approval of the institutional ethics committee and written informed consent of parents was obtained prior to enrolments of contacts.

Inclusion criteria: Children below 10 years living in same house as adult with tuberculosis

Exclusion criteria: Children who had been previously treated for tubercular infection, with comorbid conditions like HIV infection, hematological, or reticulo-endothelial system malignancies, diabetes and those who were previously or currently on immunosuppressive drugs including corticosteroids were excluded.

Detailed history noted and clinical examination of children was performed by senior resident in pediatrics. History of BCG vaccination was especially enquired after, and scars examined. Height was measured using a stadiometer (erect position for children older than 2 years and supine position for younger children); weight was recorded using a single pre-calibrated beam balance. Malnutrition classified according to the Indian Academy of Pediatrics (IAP) classification [7]: Grade 1, weight $71-80 \%$ of expected; grade 2 , weight $61-70 \%$ of expected; grade 3 , weight $51-60 \%$ of expected; and grade 4 , weight less than $50 \%$ of expected. Grades 1 and 2 were categorized as mild malnutrition and grades 3 and 4 as severe malnutrition.

Each of the children underwent tuberculin skin testing, performed by the intradermal injection of 1 Tuberculin Unit of Purified Protein Derivative PPD-RT23 with Tween 80 into the volar surface of the left forearm using a 26 gauge needle and disposable syringe.

This was read 72 hours later in good light with the forearm slightly flexed. Transverse in duration of greater than $10 \mathrm{~mm}$ was defined as a positive tuberculin test suggestive of tuberculosis infection.

A single technician trained in administration and interpretation of tuberculin test performed the procedure in all children.

All children underwent postero-anterior erect chest radiography which was reported by a single experienced radiologist (unaware of the results of tuberculin testing) and labelled as consistent or not consistent with tuberculosis.

Statistical analysis: Data analysis done by SPSS V22 software. Descriptive statistics calculated by frequency and percentage. Parameters between contacts of PTB and HIV PTB were done using Student's t test for continuous variables and the $\mathrm{x} 2$ test (with or without Yates's correction) for qualitative variables. $\mathrm{P}<0.05$ will be considered as statically significant

\section{Results}

Total of 154 children in contact with 108 index cases enrolled as subjects of which 8 children lost to follow up. Total of 146 cases were included in final analysis. The number of females $(54.1 \%)$ outnumbered the number of male subjects in the study. Majority of children were malnourished, out of which 42 (28.8\%) contacts had mild malnutrition and 57(39\%) had severe malnutrition. BCG scar was observed in 92 contacts (Table 1). In remaining contacts parents gave history of BCG vaccination but no documentation of same

Among the total subjects 81 children had exposure to adults with pulmonary tuberculosis and 65 (44.5\%) were exposed to adults with HIV and pulmonary tuberculosis.

Among the symptomatic contact most common symptom observed was chronic cough $(n=17)$ followed by documented weight loss $(n=11)$. Table 2 Children exposed to PTB adults are more symptomatic than those exposed to adults with HIV and PTB. Chest radiograph was consistent with tuberculosis in nine children, seven of whom were contacts of PTB patients.

TST positive (>10mm) in 49 contacts of which 35 contact has exposure with adults with PTB, while 14 were exposed to HIV and PTB. The difference is found to be statically significant $(\mathrm{p}=0.001)$. The effect of contact with PTB and HIV and PTB patient on the occurrence of positive tuberculin test was analysed and found to be highly significant in both the group of contacts $(\mathrm{p}>0.0001)$ (Table 3 ). Tuberculin skin test was positive in $23.8 \%, 26.3 \%$, and $29,8 . \%$ contacts with normal nutrition, mild malnutrition, and severe malnutrition respectively. The size of in duration of positive tuberculin skin test among contacts with increasing grades of malnutrition (Figure 1) 
Table-1: Demographic characteristics of study subjects.

\begin{tabular}{|c|c|}
\hline characteristic & Number \\
\hline Male & $67(45.9 \%)$ \\
\hline Female & $79(54.1 \%)$ \\
\hline Contact with PTB & $81(55.5 \%)$ \\
\hline Contact with HIV \& PTB & $65(44.5 \%)$ \\
\hline No malnutrition & $42(28.8 \%)$ \\
\hline Mild malnutrition & $57(39 \%)$ \\
\hline Severe malnutrition & $47(32.2 \%)$ \\
\hline BCG scar & $91(62.3 \%)$ \\
\hline
\end{tabular}

Table-2: Clinical characteristics in children.

\begin{tabular}{|c|c|c|c|}
\hline Clinical finding & Total & PTB contacts & HIV-PTB contacts \\
\hline Cough $>$ 4 weeks duration & 17 & 12 & 5 \\
\hline Weight loss & 11 & 7 & 4 \\
\hline Loss of appetite & 6 & 1 & 5 \\
\hline Lymphadenitis & 13 & 35 & 14 \\
\hline TST-positive & 49 & 35 \\
\hline
\end{tabular}

Table-3: Risk factors analysis in contacts

\begin{tabular}{|c|c|c|c|c|}
\hline Variable & $\begin{array}{c}\text { Infection } \\
\text { positive }\end{array}$ & $\begin{array}{c}\text { Infection } \\
\text { negative }\end{array}$ & P-value & Odd's ratio (95\% C I) \\
\hline$<5$ years & 29 & 32 & $0.002^{*}$ & $1.02(1.21-2.34)$ \\
\hline Severe malnutrition & 24 & 28 & $0.05^{*}$ & $0.47(0.21-1.06)$ \\
\hline Absence of BCG & 19 & 36 & 0.85 & $1.07(0.53-2.18)$ \\
\hline Contact with PTB & 35 & 46 & $0.0001^{*}$ & $0.36(1.10-1.74)$ \\
\hline Contact with HIV PTB & 14 & 51 & $0.0001^{*}$ & $2.77(1.33-5.79)$ \\
\hline
\end{tabular}

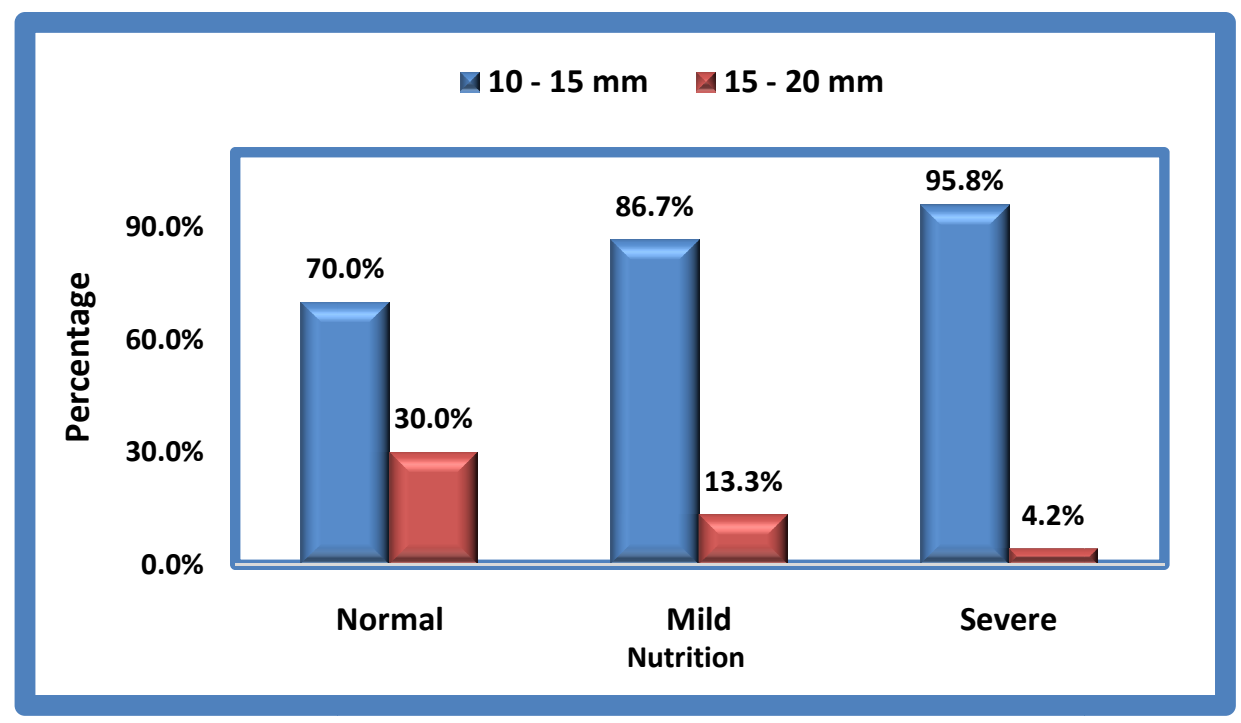

Fig 1: Nutrition 


\section{Discussion}

Exact prevalence of tuberculosis in India is not known. It is estimated that childhood TB constitutes $10-20 \%$ of all TB in high-burden countries [2]. Prevalence of tuberculosis in high risk contacts observed in this study was high $(33.6 \%)$. Similar observations made in other studies using TST cut off $>10 \mathrm{~mm}$ stressing the need for contact tracing in high risk children [8,9]. A metaanalysis of contact investigation in low- and middle income countries by Morrison and colleagues revealed a prevalence of $\mathrm{TB}$ infection of $40 \%$ in children aged under 15 years [10]. Despite high prevalence of infection contact screening rarely implemented. A cross-sectional study in India reported that only $14 \%$ children younger than 14 years living in the same house as adults with pulmonary $\mathrm{TB}$ were screened for $\mathrm{TB}$ [11].

Early identification of tubercular infection in children relies heavily on tuberculin testing despite rapid advances in the diagnosis. Tuberculin test depends on administration of reagent and interpretation of test result. Multiple persons involved in the interpretation of test may lead to varied inference. In the present study the major limitation of tuberculin test is not a factor as the test is administered and interpreted by single person.

BCG vaccine known to protect from severe tubercular infection in children. BCG scar is observed in $62.3 \%$ of subjects. Kumar et al observed BCG scar in $81 \%$ of children [12]. BCG vaccination interferes with tuberculin reactivity but in duration of $>10 \mathrm{~mm}$ in a BCG vaccinated child is more likely due to tubercular infection rather than vaccination [13, 14]. High prevalence of tubercular positivity in the present study population and majority of them having in duration $>$ $10 \mathrm{~mm}$ give indirect evidence of tubercular infection.

Malnutrition depress the hypersensitivity of Mantoux test and give false negative result [15]. Some studies reported significant difference in prevalence of Mantoux positivity among malnourished compared to normal children $[16,17]$. Malnourished child can mount hypersensitivity reaction but size of in duration will be smaller. In the present study there was a significant difference in the prevalence of positive tuberculin test among malnourished compared to normally nourished children and mean duration of in duration in severely malnourished contacts was less. Young children aged $\leq 5$ years were at significant risk of developing disease, probably because the pathogenesis of tubercular infection is different in younger than older children
[17]. Older children who were at the risk of reactivation of latent infection, younger children are usually at risk of primary disease after infection from the index case [18]. HIV epidemic has significant influence on the epidemiology of tuberculosis. Adults with TB-HIV coinfection may be less likely to infect their close contacts than HIV-negative TB cases [19,20]. Factors like duration of cough and cavitory lesion on chest radiograph, associated with transmission of tuberculosis could differ significantly between HIV-seropositive and HIV-seronegative TB patients [21, 22]. In this study HIV-TB co infected adults transmitted infection to significant more number of contacts as compared to the transmission by HIV negative TB adults.

Limitations: Smaller sample size and lack of follow up of infected children is the major drawback. All the children who were TST positive were referred to RNTCP for further evaluation and treatment.

\section{Conclusions}

The findings from the present study suggest that there is a high prevalence of infection among children in household contact with adult cases of tuberculosis. The risk is higher for contacts of HIV negative PTB patient, severe malnutrition, younger age ( $>5$ years) are significant risk factors for the transmission of infection First author was major contributor in the collection of data and compilation of data, while second author helped in planning of study and compilation of data

What this study adds to existing knowledge? Adults with co-infection (HIV-PTB) transmit infection significantly to close contacts. However, risk of transmission of infection is more in contacts of HIV negative PTB adults. Malnourished children under 5 years of age are at greater risk. Absence of BCG scar is not a risk factor.

Funding: Nil, Conflict of interest: None initiated, Permission from IRB: Yes

\section{References}

1. Global tuberculosis report2017.Geneva:World Health Organization;2017.http://apps.who.int/iris/bitstream/ 10665/259366/1/9789241565516-eng.pdf? ua=1

2. Zumla A, George A, Sharma, et al. The WHO 2014 global tuberculosis report--further to go. Lancet Glob Health. 2015 Jan; 3(1):e10-2. doi: 10.1016/S2214-109X (14) 70361-4. 
3. Yuen CM, Jenkins HE, Chang R, et al. Two methods for setting child-focused tuberculosis care targets. Public Health Action. 2016 Jun 21; 6 (2):83-96. doi: 10.5588/pha.16.0022.

4. Harries AD, Hargreaves NJ, Graham SM, et al. Childhood tuberculosis in Malawi: nationwide casefinding and treatment outcomes. Int J Tuberc Lung Dis $2002 ; 6: 424-3$

5. Enarson DA. The International Union Against Tuberculosis and Lung Disease model National Tuberculosis Programmes. Tuber Lung Dis. 1995 Apr; 76 (2): 95-9.

6. Marais BJ, Ayles H, Graham SM, et al. Screening and preventive therapy for tuberculosis. Clin Chest Med. 2009 Dec; 30 (4):827-46, x. doi: 10.1016/j.ccm. 2009.08.012.

7.ShahPM.Nutrition subcommittee of Indianacademy of pediatrics.ReportofConvenor.IndianPediatr1972;9:360

8. Sinfield R, Nyirenda M, Haves S, Molyneux EM, Graham SM. Risk factors for TB infection and disease in young childhood contacts in Malawi. Annals of tropical paediatrics. 2006 Sep 1;26(3):205-13.

9. Singh M, Mynak ML, Kumar L, Mathew JL, Jindal SK. Prevalence and risk factors for transmission of infection among children in household contact with adults having pulmonary tuberculosis. Archives of disease in childhood. 2005 Jun 1;90(6):624-8

10. Morrison J, Pai M, Hopewell PC. Tuberculosis and latent tuberculosis infection in close contacts of people with pulmonary tuberculosis in low-income and middleincome countries: a systematic review and metaanalysis. Lancet Infect Dis. 2008 Jun; 8(6):359-68. doi: 10.1016/S1473-3099(08)70071-9. Epub 2008 Apr 29.

11. Rekha B, Swaminathan S. Childhood tuberculosisglobal epidemiology and the impact of HIV. Paediatric respiratory reviews. 2007 Jun 1;8(2):99-106.

12. Kumar S,Radhakrishna CV, Jeetendra R, Kumar P, Chauhan LS, Srivastava R. Prevalence of tuberculous infection among school children in Kerala. Indian $\mathbf{J}$ Tuberc. 2009 Jan;56(1):10-6

13. Wang L, Turner MO, Elwood RK, et al. A metaanalysis of the effect of Bacille Calmette Guérin vaccination on tuberculin skin test measurements.
Thorax. 2002 Sep;57(9):804-9. DOI:10.1136/thorax.57. 9.804

14. Leung CC, Yew WW, Tam CM, et al. Tuberculin response in BCG vaccinated schoolchildren and the estimation of annual risk of infection in Hong Kong. Thorax 2005;60(2):124-9

15. Chakraborty AK, Ganapathy KT, Rajalakshmi R. Effect of nutritional status on delayed hypersensitivity due to tuberculin test in children of an urban slum community. Ind J Tub 1980;27:115-19

16. Chadha VK, Suryanarayana HV, Krishnamurthy NK, et al. Prevalence of under nutrition among periurban children and its influence on the estimation of annual risk of tuberculosis infection. Ind J Tub 1997;44: $67-71$.

17. Marais BJ, Gie RP, Schaaf HS, et al. The natural history of childhood intra-thoracic tuberculosis: a critical review of literature from the pre-chemotherapy era. Int J Tuberc Lung Dis. 2004 Apr;8(4):392-402.

18. Newton SM, Brent AJ, Anderson S, et al. Paediatric tuberculosis. Lancet Infect Dis. 2008 Aug;8(8):498-510. doi: 10.1016/S1473-3099(08)70182-8.

19. Espinal MA, Perez EN, Baez J, Henriquez L, Fernandez K, Lopez M,et al. Infectiousness of Mycobacterium tuberculosis in HIV-1-infected patients with tuberculosis: a prospective study. Lancet. 2000; 355:275-280

20. Carvalho AC, De Riemer K, Nunes ZB, et al. Transmission of Mycobacterium tuberculosis to contacts of HIV-infected tuberculosis patients. Am J Respir Crit Care Med. 2001 Dec 15;164(12):2166-71. DOI:10.1164/ajrccm.164.12.2103078

21. Small PM, Hopewell PC, Singh SP, Paz A, Parsonnet J, Ruston DC, et al. The Epidemiology of Tuberculosis in San Francisco--A Population-Based Study Using Conventional and Molecular Methods. New England Journal of Medicine. 1994 Jun 16;330 (24): 1703-9.

22. Havlir DV, Barnes PF. Tuberculosis in patients with human immunodeficiency virus infection. N Engl J Med. 1999 Feb 4;340 (5):367-73. DOI:10.1056/NEJM1 99902043400507

\section{How to cite this article?}

Saikumar B, Tarakeswara Rao P. Pediatric tuberculosis in close contacts: prospective study. Int J Pediatr Res. 2019; 6(06):267-271.doi:10.17511/ijpr.2019.i06.01 